\title{
炔丙基自由基在有机合成化学中的应用
}

\author{
路福东 ${ }^{a}$ 姜烜 ${ }^{a}$ 陆良秋*, ${ }^{*}$ 肖文精*,,$b$ \\ ( ${ }^{a}$ 华中师范大学化学学院 农药与化学生物学教育部重点实验室 武汉 430079) \\ ( ${ }^{b}$ 中国科学院上海有机化学研究所 金属有机化学国家重点实验室 上海 200032)
}

\begin{abstract}
摘要 炔烃的合成与转化一直是有机合成化学的一个重要研究内容. 其中, 炔丙位官能化是实现炔烃合成与转化的一 个重要途径. 相对于经历阳离子中间体途径的炔丙位官能化反应，自由基途径的炔丙位官能化反应在最近十年才得以 发展，且与前者也已形成互补之势. 该类炔丙基自由基既能够通过炔丙位的碳杂键断裂生成，又可通过自由基对 1,3烯炔的加成生成. 同时，由于炔丙基自由基存在自由基与炔烃的共轭结构，使得该自由基既能够直接对金属物种加成 参与炔丙位的官能化反应，又能够异构成联烯自由基后对金属物种加成，继而参与联烯化合物的合成. 此外，炔丙基 自由基还可以被进一步氧化成炔丙基阳离子后参与后续的有机转化. 本综述根据炔丙基自由基所参与的反应类型，对 近年来炔丙位自由基参与的有机反应进行了简要总结.
\end{abstract}

关键词 炔丙基自由基; 炔丙位官能化; 炔烃; 联烯; 过渡金属催化

\section{Application of Propargylic Radicals in Organic Synthesis}

\author{
Lu, Fu-Dong $^{a} \quad$ Jiang, Xuan $^{a} \quad$ Lu, Liang-Qiu* ${ }^{* a} \quad$ Xiao, Wen-Jing*,a,b \\ $\left({ }^{a}\right.$ Key Laboratory of Pesticide \& Chemical Biology Ministry of Education and College of Chemistry, Central China Normal \\ University, Wuhan 430079) \\ $\left({ }^{b}\right.$ State Key Laboratory of Organometallic Chemistry, Shanghai Institute of Organic Chemistry, Chinese Academy of \\ Sciences, Shanghai 200032)
}

\begin{abstract}
The production and transformation of alkynes occupys an important position in organic synthetic chemistry. Within this realm, propargylic functionalization of alkynes is a feasible way towards this purpose. Especially, the propargylic functionalization via radical pathways has flourished in the last decade, which is believed to be a significant complement to the classic metal-catalyzed propargylation reaction involving cationic intermediates. According to the reaction modes, these advancements will be highlighted by classifying into four types. The first one is the propargylic functionalization reactions involving propargylic radicals. Generally, propargylic radicals can be generated through single electron reduction of alkyne substrates by low-valence metal catalysts or excited state of photocatalysts, then participated in the following cross-coupling reactions to achieve alkyne products. In this part, asymmetric variants have been also well developed. The second one is the preparation of allene compounds through the allenyl radical pathway. For these processes, propargylic radicals can isomerize to allenyl radicals, which can participate in the copper- or nickel-catalyzed coupling reaction to produce significant allene compounds. The third one is the dehydrative alkylation reaction of propargyl alcohols that involve propargylic radical intermediates, too. Such radical intermediates can be further oxidized to propargylic cation intermediates, followed by a deprotonation to form substituted 1,3-enyne compounds. The forth one is the synthesis of vinylic alkoxyamines through a propargylic radical route. Initially, propargyl alcohols can be converted to propargylic radical species by the joint action of copper catalysts and TEMPO. The generated propargylic radical species can be captured by TEMPO to form vinylic alkoxyamines. Finally, an outlook on the radical propargylic functionalizations will be provided at the end of this review.
\end{abstract}

Keywords propargylic radical; propargylic functionalization; alkyne; allene; transition metal catalysis

\section{1 引言}

炔烃作为一类重要的不饱和官能团, 广泛存在于许 多天然产物、药物分子和功能材料中. 并且, 由于炔烃 这一类官能团结构的特殊性, 能够实现向烷烃、烯烃、 醇、酮以及芳环等其它许多化合物的转化. 因此, 炔烃 化合物的合成与转化一直是合成化学学科的一个重要

\section{研究领域 ${ }^{[1]}$.}

炔丙位的官能化反应是实现炔烃合成与转化的一 种重要途径, 并已经取得了重要的发展与应用 ${ }^{[2]}$. 早在 1972 年, Nicholas 等 ${ }^{[3]}$ 就已经实现了炔丙醇及其衍生物 的炔丙位官能化反应. 这类反应主要经历了钴稳定的炔 丙基正离子中间体，并且被广泛用于天然产物和药物分

* E-mail: luliangqiu@mail.ccnu.edu.cn; wxiao@mail.ccnu.edu.cn

Received June 8, 2019; published August 13, 2019.

Project supported by the National Natural Science Foundation of China (Nos. 21572074, 21772052 and 21772053) and the Natural Science Foundation of Hubei Province (Nos. 2015CFA033, 2017AHB047).

项目受国家自然科学基金(Nos. 21572074, 21772052, 21772053)和湖北省自然科学基金(Nos. 2015CFA033, 2017AHB047)资助. 
子的合成. 此外, 钴稳定的炔丙基自由基中间体也有所 报道, 主要被用于炔丙基自由基的偶联反应当中 ${ }^{[4]}$. 美 中不足的是，该类方法需要用到当量的有毒金属试剂、 多步的操作且产生当量的金属废弃物. 1994 年, Caporusso 等 ${ }^{[5]}$ 首次实现了铜催化的炔丙位胺化反应, 为后期 催化不对称的炔丙位官能化反应打下了坚实的基础. 在 随后的二十多年时间里, 这一领域由于 Nishibayashi, 侯雪龙, 胡向平等许多化学家持续不断的努力得到了快 速的发展, 并有多篇综述总结了该领域的进展 ${ }^{[2,6]}$. 需要 指出的是, 这些方法大都经过 $\gamma$ 位具有亲电性的亚丙二 烯基金属物种中间体, 这就意味着非端炔类化合物难以 参与该类反应 ${ }^{[7]}$. 而炔丙基自由基所参与的炔丙基化反 应刚好填补了这一空缺, 能够用于非端炔类化合物的炔 丙位官能化反应，具有十分重要的合成意义. 问题在于, 由于炔丙基自由基的炔烃片段与自由基共轭, 使得炔丙 基自由基不仅能够直接参与到炔丙位官能化反应中(产 生中心手性), 也能够发生自由基迁移异构为联烯自由 基之后参与到后续偶联反应, 从而构建烯类化合物(产 生轴手性). 此外, 由于炔丙基自由基丰富的反应位点 和模式, 还可以产生烯炔等其它不同结构的产物. 因此, 化学选择性控制和立体选择性控制是自由基途径炔丙 位官能化的难点和关键所在. 本综述依据炔丙基自由基 所参与的反应类型, 对近年来炔丙基自由基参与的反应 进行了总结(图 1).

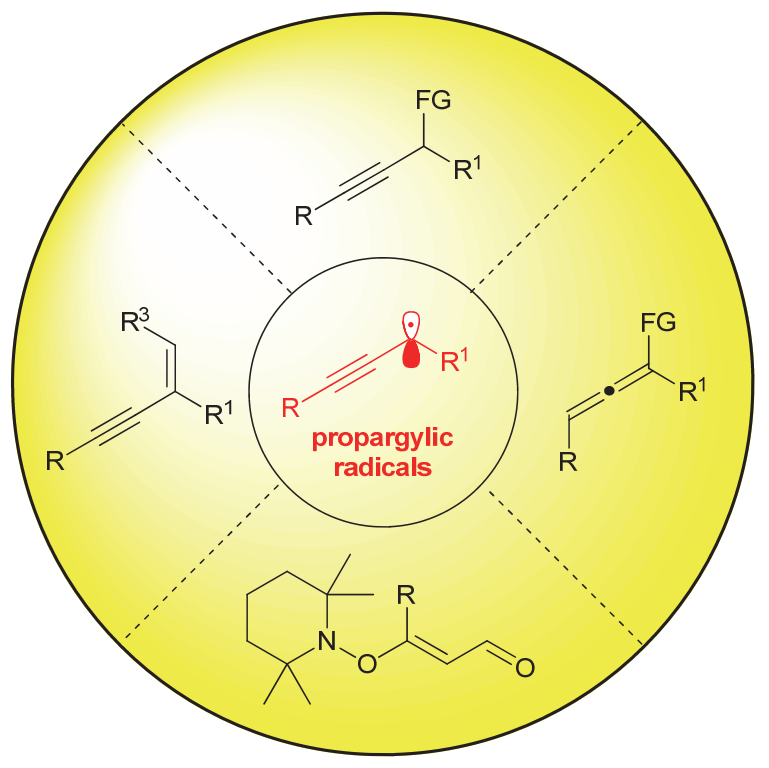

图 1 炔丙基自由的转化(FG: 官能团)

Figure 1 Transformations of propargylic radicals (FG: functional group)

\section{2 炔丙基自由基参与的炔丙位官能化反应}

1977 年, Kropf 等 ${ }^{[8 a]}$ 报道了一例 Kharasch 类型的炔 丙位官能化反应, 在铜盐和过氧酯的存在下能够实现内 炔类化合物的炔丙位 $\mathrm{C}-\mathrm{H}$ 键氧化反应. 2007 年, Christ 和 Sorokin 团队 ${ }^{[8 b]}$ 运用类似的策略实现了烯丙位和炔丙
位的选择性 $\mathrm{C}-\mathrm{H}$ 键氧化反应. 值得注意的是, 作者通 过使用手性配体能够以较高的收率和中等的对映选择 性得到手性的烯丙位氧化产物, 但炔丙位氧化产物的 $e e$ 值最高只能达到 4\%(图 2).<smiles>[R]CC#C[I+]</smiles>

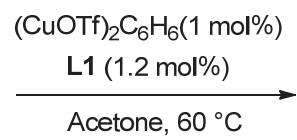<smiles>CCCC1COC(c2cccc(C3=NC(C(C)C)CO3)n2)=N1</smiles><smiles>[R]C#CC([R])OC(=O)c1ccccc1</smiles>
42\% 99\% yields

图 2 Kharasch 类型的炔丙位 $\mathrm{C}-\mathrm{H}$ 键氧化反应

Figure 2 Kharasch-type propargylic $\mathrm{C}-\mathrm{H}$ bond oxidation

2008 年, $\mathrm{Fu}$ 等 ${ }^{[9]}$ 实现了镍催化的二级炔丙基溴化物 与芳基锌试剂的不对称 Negishi 交叉偶联反应. 该反应 在 $\mathrm{NiCl}_{2} \bullet$ glyme 为催化剂、狮取代的手性吡啶双啞唑啉 $\mathbf{L 2}$ 为配体的条件下, 能够实现消旋炔丙基溴代物到手 性炔丙位芳基化产物的转化. 该反应表现出较好的底物 普适性，带有酯基或烯基等官能团的炔丙基溴代物均能 很好地适用于该反应，以较高的收率和对映选择性生成 目标化合物(图 3, a). 2012 年, $\mathrm{Fu}$ 等 ${ }^{[10]}$ 利用类似的策略实 现了炔丙酯类化合物的不对称 Negishi 交叉偶联反应 (图 3,b). 相比之前的工作，该反应条件更加温和，且同 样具有较好的底物普适性. 这类镍催化的不对称炔丙基 偶联反应已成为有机化学中一种有效的合成手段. 例 如, $\mathrm{Fu}$ 教授将该策略成功应用于药物中间体的合成中. 其通过将商业可得的 4-三甲基硅基-3-丁基-2-醇 10 转化 成炔丙基溴，然后与 3,4,5-三甲氧基苯基锌 11 偶联，最 终以 $93 \%$ 的 $e e$ 值合成得到二氢叶酸还原酶抑制剂的关 键中间体 13(图 4) ${ }^{[11]}$.

a)
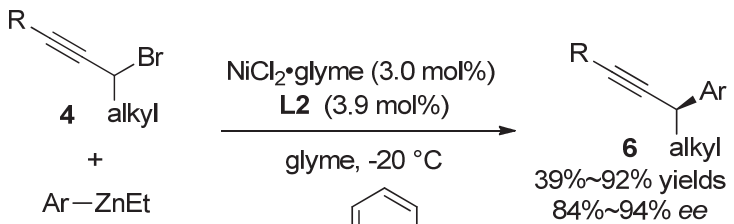

5

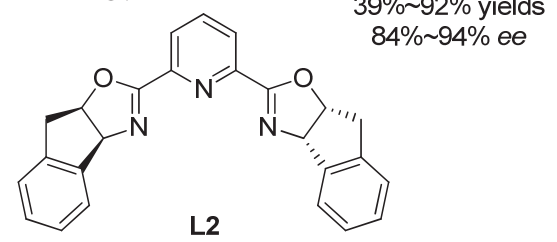

b) TMS

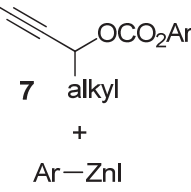

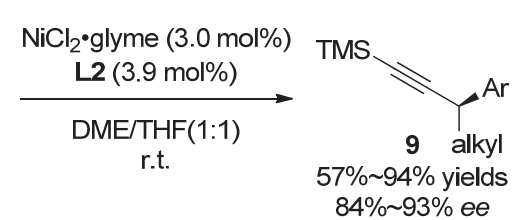

$\mathrm{Ar}^{1}=2,4,6$-trimethoxyphenyl

图 3 镍催化的不对称炔丙位芳基化反应

Figure 3 Nickel-catalyzed asymmetric propargylic arylations 
<smiles>CC#CC(C)O</smiles>

10<smiles>C#CC(C)c1cc(OC)c(OC)c(OC)c1</smiles>

3) $\mathrm{K}_{2} \mathrm{CO}_{3}$<smiles>COc1cc(C(C)C#Cc2c(C)nc(N)nc2N)cc(OC)c1OC</smiles><smiles>CCCc1cc(OC)c(OC)c(OC)c1</smiles>

图 4 二氢叶酸还原酶抑制剂 13 的催化不对称合成

Figure 4 Catalytic asymmetric synthesis of a potent dihydrofolate reductase inhibitor

2014 年, $\mathrm{Fu}$ 等 ${ }^{[12]}$ 对他所发展的镍催化不对称炔丙 位芳基化反应进行了详细的机理研究. 作者通过 $\mathrm{EPR}$ (电子顺磁共振波谱)实验、TEMPO(2,2,6,6-四甲基哌 啶氧化物)捕获实验等验证了该反应体系中一价镍物种 以及炔丙基自由基的存在, 为该反应提出了一个合理的 机理. 如图 5 所示, 一价镍物种首先与炔丙基溴代物发 生单电子转移, 生成炔丙基自由基 16 和二价镍物种 $\mathbf{1 7}$; 接着, 该物种与芳基锌试剂 18 发生转移金属化并生成 二价的芳基镍物种 20; 随后, 炔丙基自由基 16 对芳基 镍物种加成生成三价镍物种 21 , 该三价镍物种还原消 除生成目标产物 22 以及一价镍物种, 最终完成催化循 环.

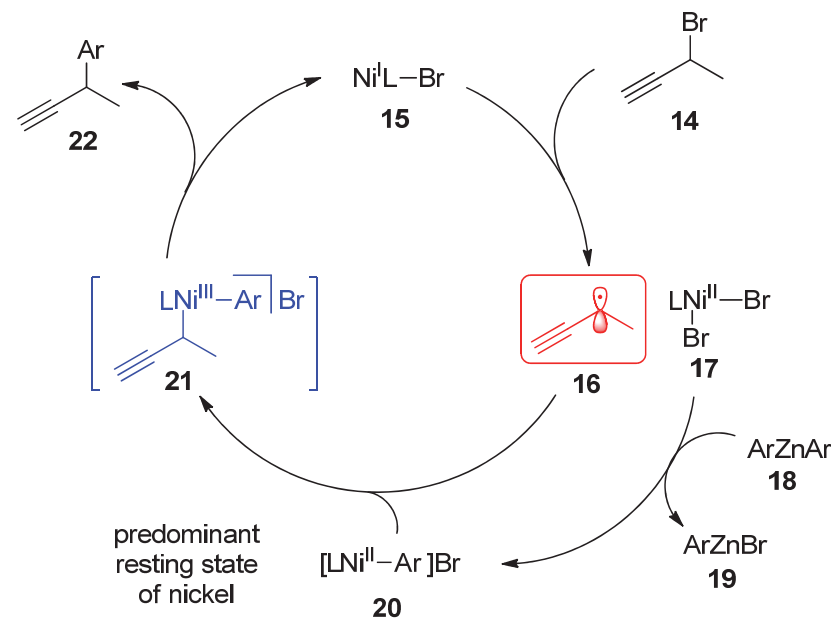

图 5 镍催化炔丙位芳基化反应的机理

Figure 5 Mechanism of the Nickel-catalyzed propargylic arylation

2018 年, Cárdenas 等 ${ }^{[13]}$ 运用铁催化的方法实现了炔 丙基溴代物与烷基格氏试剂的 Kumada-类型偶联反应. 该反应仅需 $1 \mathrm{~h}$ 就能达到最高 $83 \%$ 的收率, 但作者无法 完全抑制炔丙位自由基向联烯自由基的异构. 因此，产 物中总会混杂一定的联烯产物(图 6).

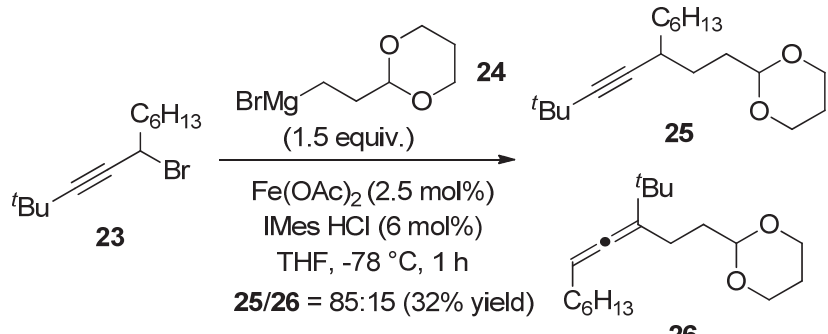

26

图 6 铁催化的炔丙位烷基化反应

Figure 6 Iron-catalyzed propargylic alkylations

2018 年，张新刚等 ${ }^{[14]}$ 利用铁催化实现了芳基金属 试剂的二氟烷基化反应，其中偕二氟炔丙基溴类化合物 也能够很好地参与到该反应中, 并以较高的收率得到炔 丙位官能化的产物. 值得注意的是，当使用雌炔醇衍生 的二氟炔丙基溴底物时，该反应能够以 $65 \%$ 的收率得到 目标产物，表明该策略对复杂生物分子的修饰也具有很 好的效果(图 7).
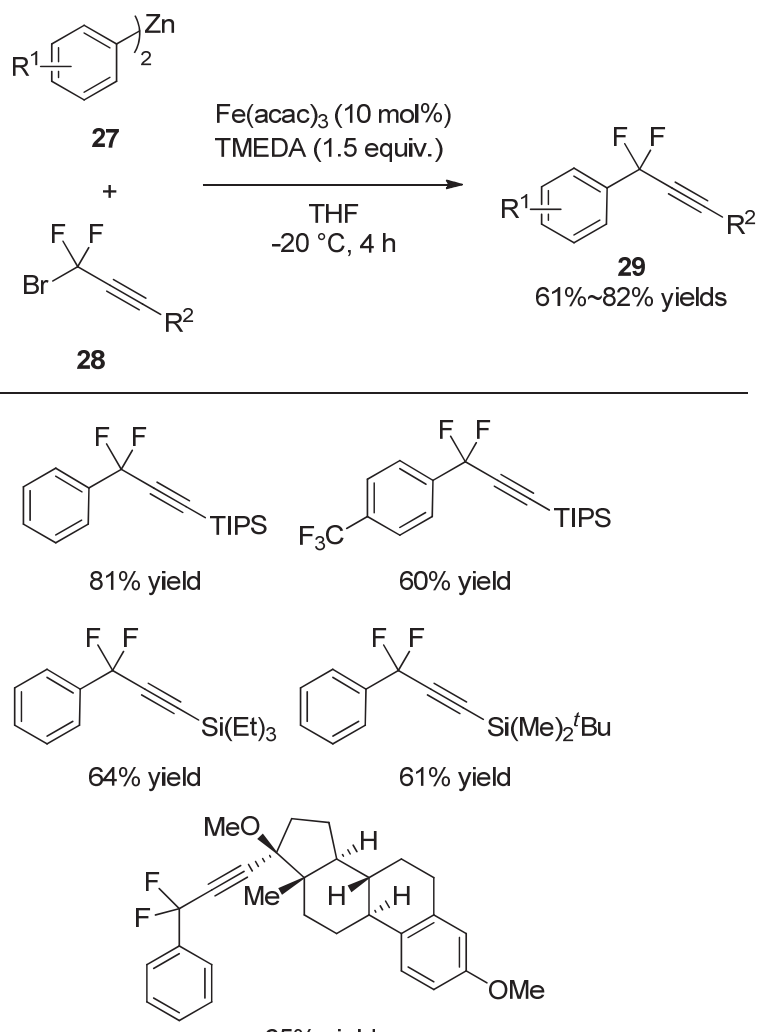

$65 \%$ yield

图 7 铁催化的炔丙位芳基化反应

Figure 7 Iron-catalyzed propargylic arylations

2019 年，肖文精、陆良秋等 ${ }^{[15]}$ 利用协同的可见光催 化和铜催化策略，实现了不对称的炔丙基自由基氰基化 反应. 该反应利用副产物羧酸负离子来活化三甲基氧硅 烷，以达到缓慢释放氰基负离子的作用，从而避免了高 浓度氧基负离子与铜配位导致金属催化剂失活的问题 (图 8). 该反应不仅能够实现苯乙炔类化合物的炔丙位 氰基化，也能实现烷基炔烃、三甲基硅乙炔类化合物的 
炔丙位氭基化反应，具有较好的底物普适性和官能团耐 受性. 此外，作者通过与重庆大学的蓝宇教授合作，通 过实验和理论计算研究了该反应的自由基途径并且对 立体选择控制做出了合理的解释. 如图所示, 作者认为 激发态的有机光催化剂 Ph-PTZ 在光照条件下到达激发 态, 随后与炔丙酯底物 30 发生单电子转移生成炔丙基 自由基 33 和氧化态的光催化剂 $\mathrm{Ph}-\mathrm{PTZ}^{+}$; 该氧化态的光
催化剂将一价的氰基铜 38 氧化成二价的氰基铜物种 $\mathbf{3 4}$, 炔丙基自由基 33 随后对 34 加成，最后通过还原消除得 到手性的炔丙腈类化合物 32 .

除了通过炔丙位碳杂键的断裂生成自由基外，通过 自由基对 1,3-烯炔的双键部分加成也是产生炔丙基自由 基的重要途径. 2015 年, Loh 等 ${ }^{[16]}$ 实现了铜或钴催化的 1,3-烯炔类化合物烯烃片段的双官能化反应(图 9). 在该

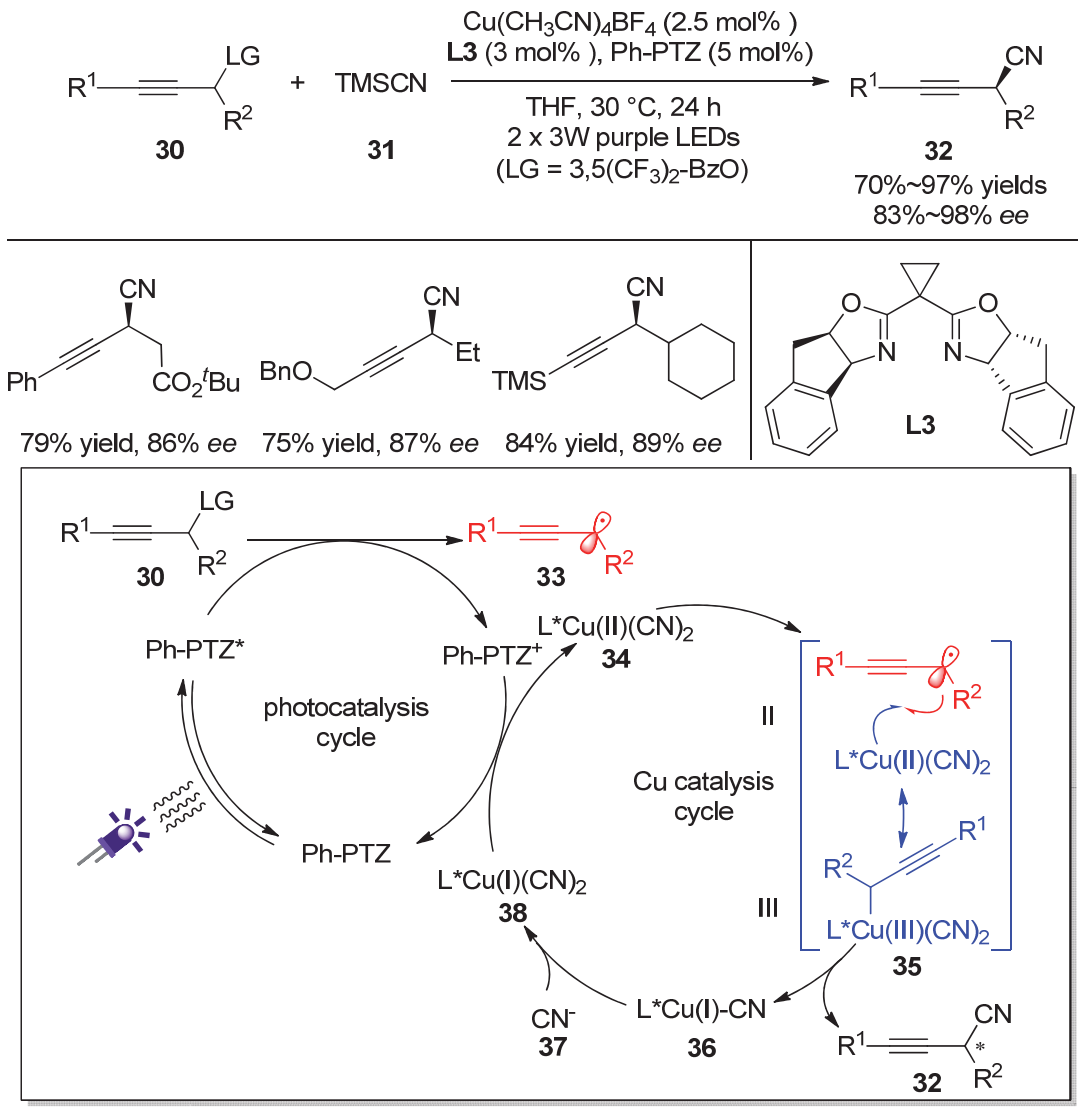

图 8 可见光催化和铜催化协同作用的不对称炔丙位氰基化反应

Figure 8 Asymmetric propargylic cyanation enabled by synergetic photoredox and copper catalysis
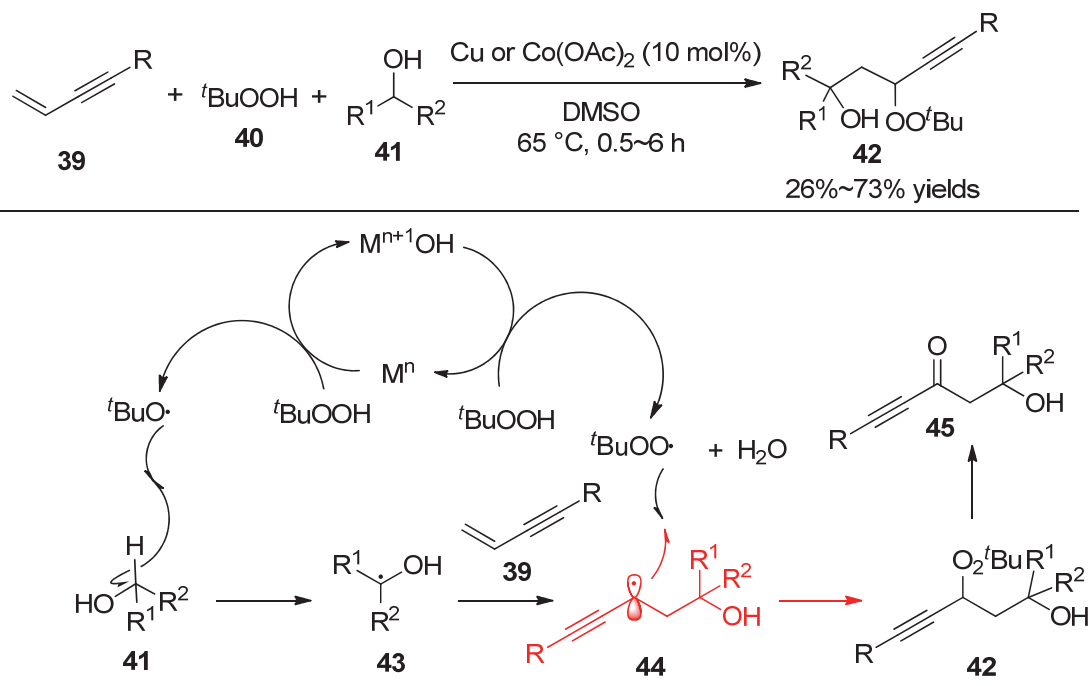

图 9 铜催化和钴催化的 1,3-烯炔的过氧化-氧烷基化反应

Figure 9 Copper- and cobalt-catalyzed peroxidation-oxyalkylation reactions of 1,3-enynes 
反应中, 铜或钴起到催化产生叔丁氧基自由基以及叔丁 过氧自由基的作用. 叔丁氧基自由基通过睢取醇的氧 $\alpha$ 位氢原子产生氧 $\alpha$ 位碳自由基 $\mathbf{4 3}$, 该自由基对 1,3-烯炔 39 的烯烃部分加成后产生炔丙基自由基 44. 随后, 该自 由基与叔丁过氧自由基发生偶联并生成最终的烯烃双 官能化产物 42. 反应所得到的 $\beta$-过氧醇可以通过简单 的转化得到 $\beta$-差基酮以及 1,3 -炔丙二醇化合物.

2015 年, Woerpel 等 ${ }^{[17]}$ 通过铜催化实现了 1,3-烯炔 烯烃片段的氧化反应. 该反应以氧气作为绿色氧化剂, $N$-羟基邻苯二甲酰亚胺(NHPI)和 $N$-羟基苯并三唑 $(\mathrm{HOBt})$ 作为自由基前体, 能够以中等的收率给出 $\alpha$ 氧代 炔丙酮类化合物(图 10).

2016 年, Woerpel 等 ${ }^{[18]}$ 又运用类似的策略实现了炔 丙位的过氧化反应, 并提出了以下可能的机理: 首先, NHPI 转变为氮氧自由基(PINO)后对 1,3-烯炔的烯烃片 段进行加成并生成炔丙位自由基 54, 随后被氧气捕获 生成过氧自由基 55; 该物种睢取 NHPI 中的氢原子生成 最终产物并且产生一分子 PINO 继续参与后续反应(图 11).
2017 年, Loh 等 ${ }^{[19]}$ 应用类似的策略实现了铁催化的 1,3-烯炔类化合物烯烃片段的过氧化一氨甲酰化反应(图 12). 值得注意的是，该反应不仅能够适用于 1,3-烯炔类 化合物，也能够适用于普通的芳基烯烃和 1,3-二烯类化 合物的烯烃双官能化，具有较好的底物普适性.

\section{3 炔丙基自由基参与的联烯类化合物的合成}

当炔丙基自由基异构成为联烯基自由基后，其参与 的偶联反应便能实现另一类重要不饱和化合物一一联 烯的合成 ${ }^{[20]}$. 1993 年, Blechert 等 ${ }^{[21 a]}$ 实现了从炔丙基自 由基到联烯自由基的转化，并将其运用到环化反应当 中. 在该反应中, $\mathrm{AIBN}$ 和 $\mathrm{Bu}_{3} \mathrm{SnH}$ 联用可以生成锡自由 基，进而篗取炔丙位的溴原子并产生炔丙基自由基 60; 随后，该自由基异构为联烯自由基 61 后发生 5-exe-trig 环化，最终通过氢原子算取后生成目标产物 62a 和 62b(图 13). 2006 年, Zard 等 ${ }^{[21 b]}$ 也运用类似的策略构建 了带有联烯结构的并环化合物.
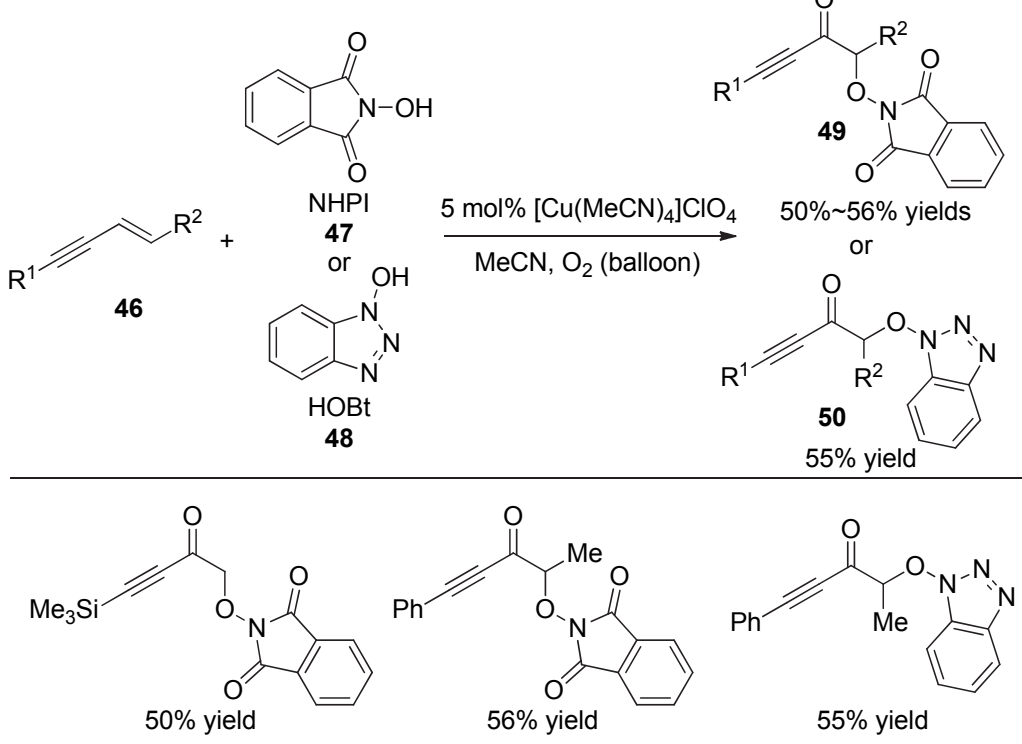

图 10 铜催化的 1,3-烯炔的氧化反应

Figure 10 Copper-catalyzed oxidation reactions of 1,3-enynes
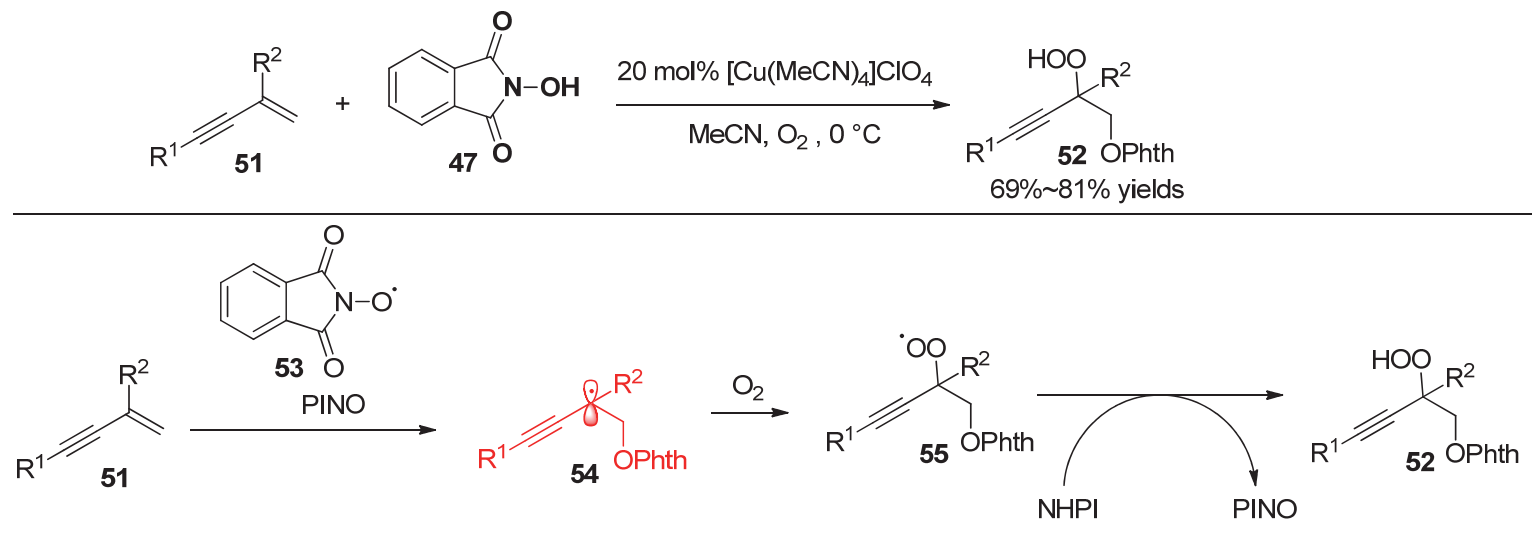

图 11 铜催化 1,3-烯炔的过氧化反应

Figure 11 Copper-catalyzed peroxidation reactions of 1,3-enynes 


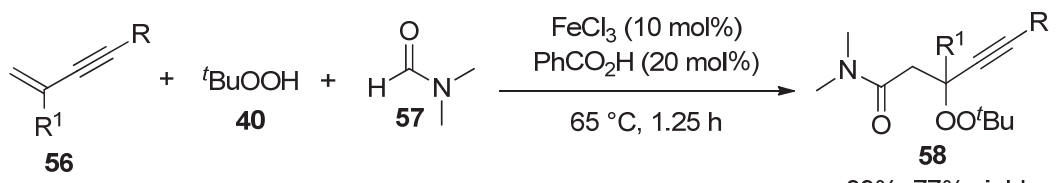

$39 \% \sim 77 \%$ yields

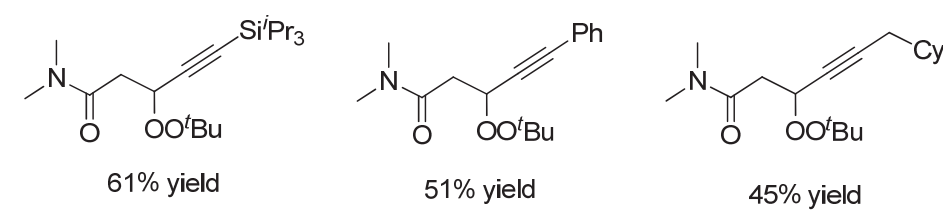

图 12 铁催化 1,3-烯炔的过氧化-氨甲酰化反应

Figure 12 Iron-catalyzed peroxidation-carbamylation reactions of 1,3-enynes

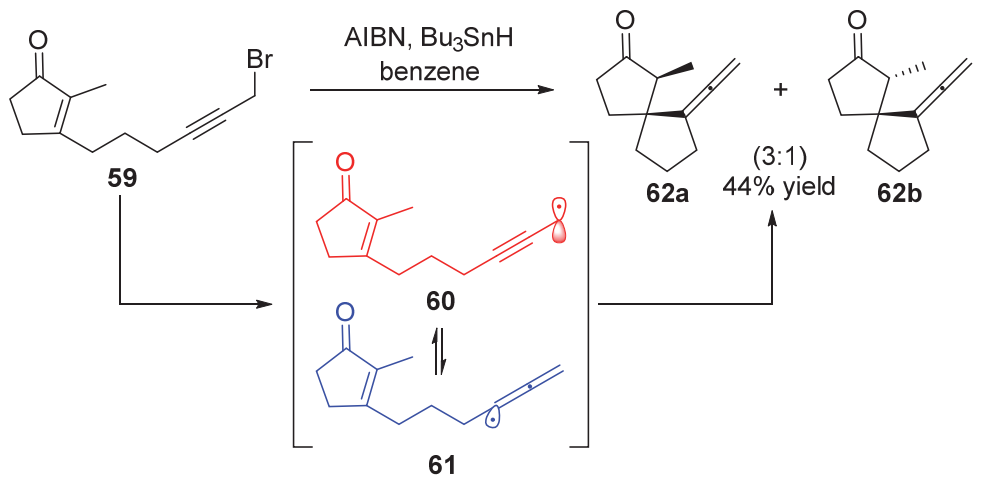

图 13 AIBN 引发的炔丙位自由基到联烯自由基的异构

Figure 13 Isomerization of propargylic radical to allene radical initiated by AIBN

2016 年, Cárdenas 等 ${ }^{[22]}$ 运用镍催化的方法实现了炔 丙基溴代物与烷基格氏试剂的偶联反应. 与 $\mathrm{Fu}$ 等工作 不同的是, 作者使用菲罗啉类配体 $\mathbf{L} 4$ 时, 能够选择性 地得到联烯类产物(图 14).

2017 年, 刘国生等 ${ }^{[23]}$ 率先实现了 1,3 -烯炔类化合物 的三氟甲基氧基化反应, 以高收率和高区域选择性得到 了联烯腈类化合物. 该反应具有广泛的底物适用范围以 及良好的官能团兼容性(图 15, a). 有意思的是, 当使用 配体 L5 和 $\mathbf{L 6}$ 时, 可以分别得到 1,3-烯炔的 1,2 位官能
化和 1,4 位官能化的产物. 对此, 作者通过详细的机理 研究, 阐述了生成两种不同产物所经历的可能路径. 与 此同时，作者也对该反应的催化不对称的过程进行了初 步探究. 当使用手性的双噁唑啉配体 L5 时, 能够以 $78 \%$ 的收率和 $73 \%$ 的 $e e$ 值得到手性的联烯腈类化合物 (图 15, b). 为了进一步了解反应的机理, 作者将含有三 元环结构的 1,3-烯炔底物 72 投入到反应中, 发现当使用 双噁唑啉配体 L5 时, 生成的三元环开环产物 74 多于联 烯腈产物 73，而当使用菲罗啉类配体 L6 时，反应则<smiles>[R]C#CC(C)Br</smiles><smiles>[R]C(=CC)CCC1OCCCO1</smiles><smiles>c1ccc(-c2ccnc3c2ccc2c(-c4ccccc4)ccnc23)cc1</smiles>
$1 \% \sim 87 \%$ yields<smiles>CC=CC(=CC)c1ccccc1</smiles><smiles>CC=C=C(CCC1OCCCO1)c1ccc(C#N)cc1</smiles>

$87 \%$ yield<smiles>CC=C=C(CCC1OCCCO1)C1CCCCC1</smiles>

$69 \%$ yield

图 14 镍催化 1,3-烯炔的 1,4-双官能化反应

Figure 14 Nickel-catalyzed 1,4-difunctionalization of 1,3-enynes 

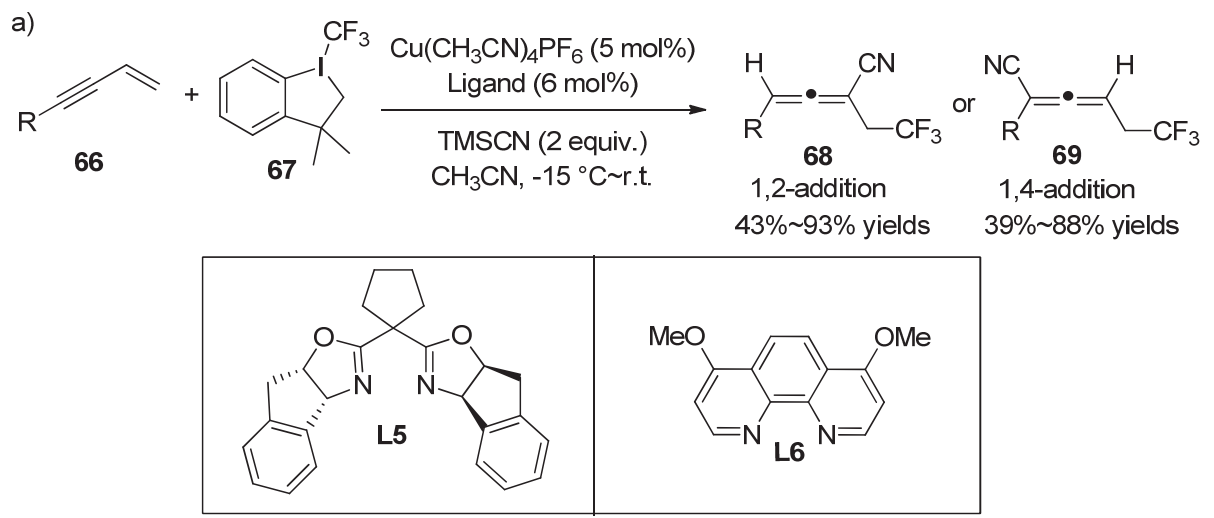<smiles>CCOCCN1C(=O)c2ccccc2C1=O</smiles>

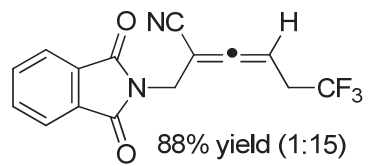<smiles>N#C/C(=C/CCOC(=O)/C=C/c1ccccc1)CC(F)(F)F</smiles><smiles>CCN(CC)CCOC(=O)C=Cc1ccccc1</smiles>

b)

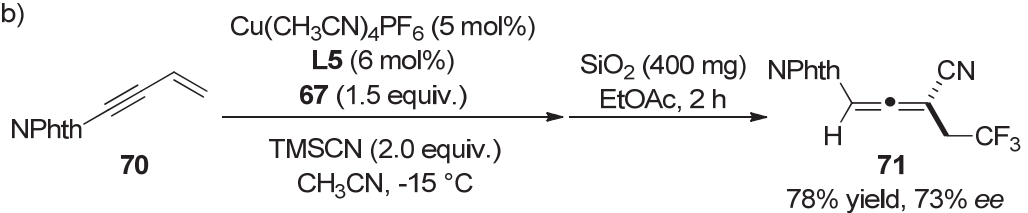

c)
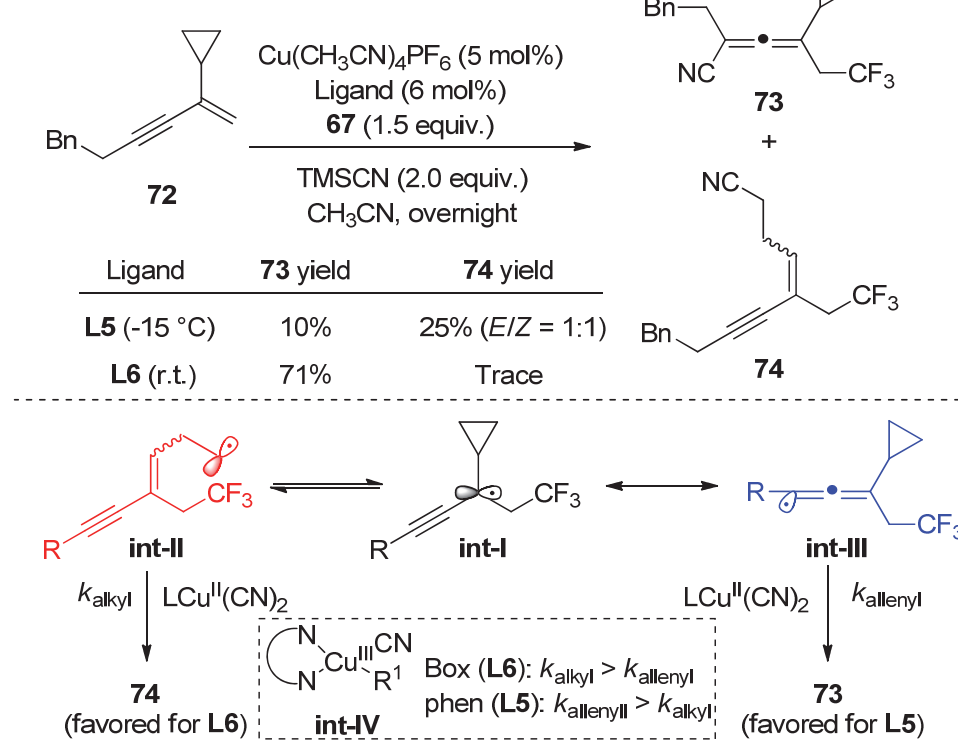

图 15 铜催化 1,3-烯炔的 1,2-和 1,4-双官能化反应

Figure 15 Copper-catalyzed 1,2-and 1,4-difunctionalization of 1,3-enynes

主要得到未开环的联烯腈产物. 基于该实验, 作者认为 该反应存在炔丙基自由基到联烯自由基的异构过程，并 且烷基自由基更倾向与 $(\mathrm{Box}) \mathrm{Cu}^{\mathrm{II}}(\mathrm{CN})_{2}$ 中间体作用, 而 联烯自由基则更倾向与(phen) $\mathrm{Cu}^{\mathrm{II}}(\mathrm{CN})_{2}$ 中间体作用并最 终生成联烯腈产物. 作者也通过理论计算为该反应路径
提供了理论支持(图 15, c).

2019 年，鲍红丽等 ${ }^{[24]}$ 运用铜催化的自由基加成/偶 联策略实现了 1,3-烯炔向联烯腈类化合物的转化(图 16). 作者发展了一种生成联烯自由基的通用方法并实现了 其在分子间 1,3-烯炔的 1,4-碳氰化和 1,4-亚磺酰亚胺化 
反应中的应用. 这类多取代的联烯可以通过简单的后期 转化得到许多其它具有重要合成价值的化合物, 如: 氟 化乙烯基氰化物、内酯、官能化的联烯酰胺、1-氨基荎 等. 此外, 作者通过 TEMPO 捕获实验、自由基 Clock 实验验证了反应途径中联烯自由基的存在, 并且在 DFT 理论计算等手段的辅助下提出了合理的反应途径. 首 先, 自由基前体 80 被一价铜单电子还原得到自由基物 种 81 和二价铜, 该自由基物种对 1,3-烯炔 75 进行加成
得到联烯自由基 84; 然后，二价铜物种与 TMSCN 发生 转移金属化得到二价的异氰铜物种 82 , 该异氧铜物种 随后与联烯自由基作用得到联烯腈类化合物 79.

同年, 鲍红丽等 ${ }^{[25]}$ 还实现了 1,3 烯炔的 1,4-烷基芳 基化反应(图 17). 该反应通过使用过氧化月桂酰类化合 物(LPO)作为烷基自由基前体，芳基硼酸作为芳基亲核 试剂, 在铜催化下以中等到较好的收率得到四取代联烯 类化合物.

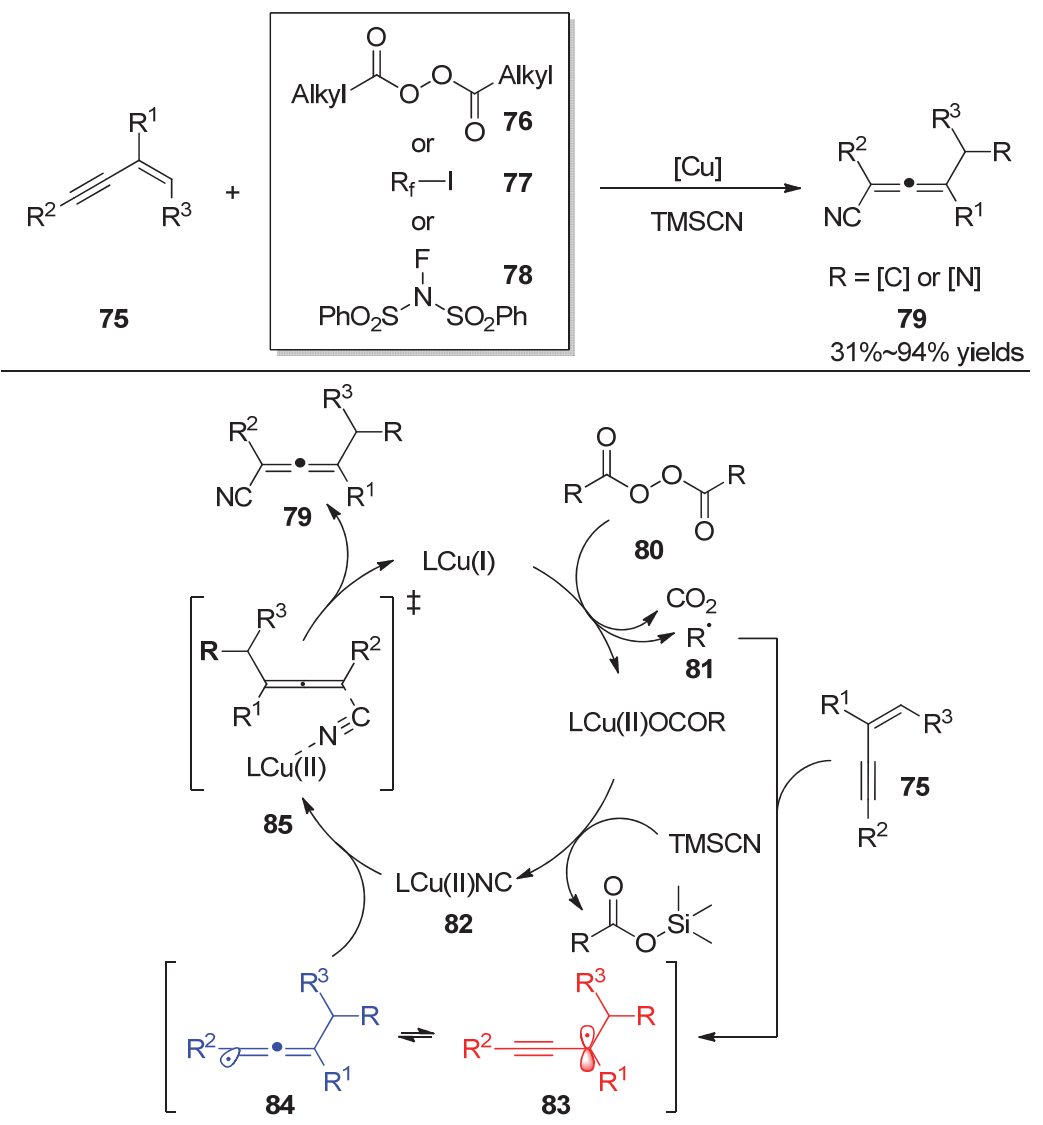

图 16 铜催化 1,3-烯炔的 1,4-双官能化反应

Figure 16 Copper-catalyzed 1,4-difunctionalization of 1,3-enynes
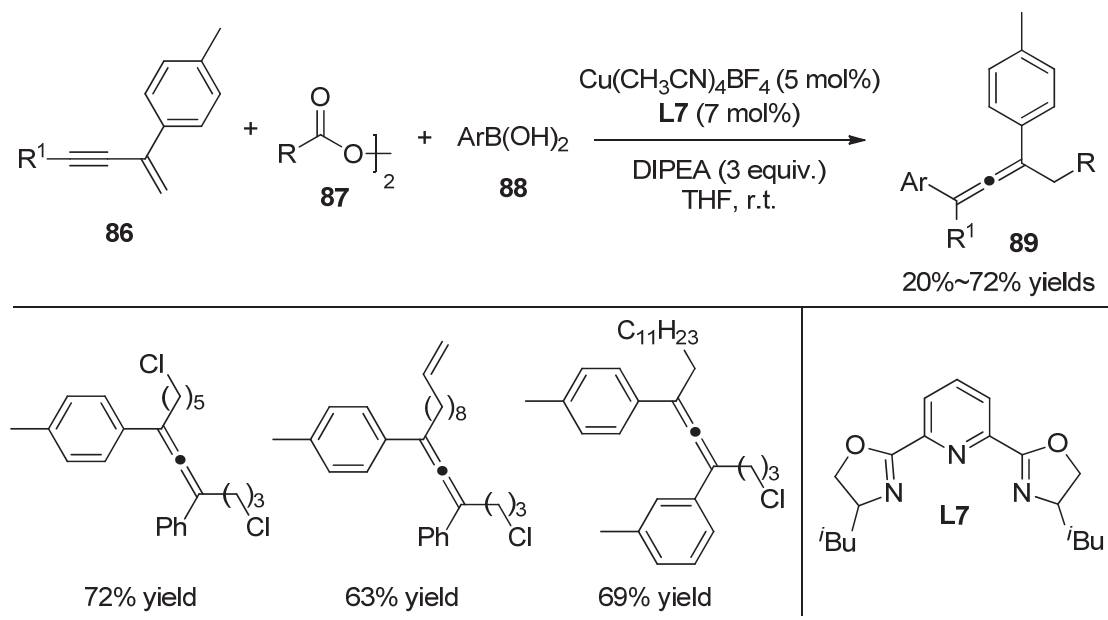

图 17 铜催化 1,3-烯炔的 1,4-烷基芳基化反应

Figure 17 Copper-catalyzed 1,4-alkylarylation of 1,3-enynes 
2019 年, 王细胜等 ${ }^{[26]}$ 报道了镍催化的 1,3-烯炔的碳 氟烷基化反应(图 18). 该反应利用简单易得的 1,3-烯炔 和二氟烷基卤代物, 合成了二氟烷基取代的联烯类化合 物, 具有条件温和、底物范围广泛、官能团兼容性好等 优势. 该反应机理如下: 一价镍催化剂首先与芳基硼酸 发生转移金属化生成一价芳基镍物种 93, 该物种随后 将二氟烷基卤代物还原得到二氟烷基碳自由基 95 以及 二价的芳基镍物种 94; 随后, 二氟烷基碳自由基对 1,3烯炔加成产生炔丙位自由基 96, 然后经过自由基迁移 生成联烯自由基 97, 而该自由基中间体对二价芳基镍 物种加成并通过还原消除得到最终的产物. 作者通过 TEMPO 捕获实验以及自由基 Clock 反应验证了反应过 程中二氟烷基自由基的存在.

\section{4 炔丙基自由基参与的炔丙醇脱水烷基化反应}

炔丙基自由基除了可以直接对金属络合物加成或 异构为联烯自由基后再对金属络合物加成外，还可以进 一步被氧化为炔丙基正离子中间体，从而进一步脱质子 形成取代的 1,3-烯炔类化合物. 2018 年, 鲍红丽等 ${ }^{[27]}$ 实 现了炔丙醇与二烷基过氧化物的脱水脱羧偶联反应(图 19). 该反应从简单的炔丙醇出发, 在铁催化的条件下 实现了多种取代的 1,3-烯炔类化合物的合成. 同时, 该 反应表现出较好的底物兼容性, 芳基炔丙醇以及烷基炔 丙醇都能很好地参与到反应中, 且具有较好的官能团兼 容性，带有烯烃、炔烃、羰基、卤素的烷基过氧化物都 能很好地参与反应. 铁催化剂被认为既起到了单电子催 化的作用, 又起到了路易斯酸催化的作用. 首先, 炔丙
醇 99 在三价铁的活化下脱去一分子水生成 1,3-烯炔中 间体 103, 过氧化物被二价铁还原后同时产生叔丁氧基 负离子和羧基自由基; 后者脱去一分子二氧化碳生成烷 基自由基，该自由基对 1,3-烯炔 103 加成生成炔丙位自 由基 104. 然后，该自由基被三价铁氧化成炔丙基正离 子 105 , 并被叔丁氧基负离子睧取质子后生成最终的 1,3-烯炔类产物.

\section{5 炔丙基自由基参与的乙烯基烷氧胺类化合物 的合成}

2019 年, Jang 等 ${ }^{[28]}$ 通过铜催化实现了四甲基哌啶氮 氧化物(TEMPO)对炔丙醇的加成反应，合成了乙烯基烷 氧胺类化合物(图 20). 在该反应中, 芳基或烷基取代的 炔丙醇都能够较好地参与到反应中。作者通过控制实验 排除了经历炔醛中间体的反应过程, 并且验证了底物中 羟基以及炔烃官能团的重要性. 具体机理如图所示: 首 先, $\mathrm{Cu}(\mathrm{OAc})_{2}$, 炔丙醇底物和 TEMPO 共同作用生成三 中心两电子的 $\mathrm{Cu}(\mathrm{II})-\mathrm{TEMPO}$ 自由基加和物 109; 随后, TEMPO 篗取炔丙醇氧 $\alpha$ 位的氢原子后生成炔丙基自由 基中间体 110, 并异构为联烯自由基 111; 随后，另一分 子 TEMPO 与联烯自由基 111 偶联生成联烯醇铜中间体 112, 解离后经过烯醇互变生成乙烯基烷氧胺类产物.

\section{6 小结与展望}

综上所述，近年来炔丙基自由基参与的化学转化得 到了较好的发展. 不仅通过自由基途径实现了非端炔类
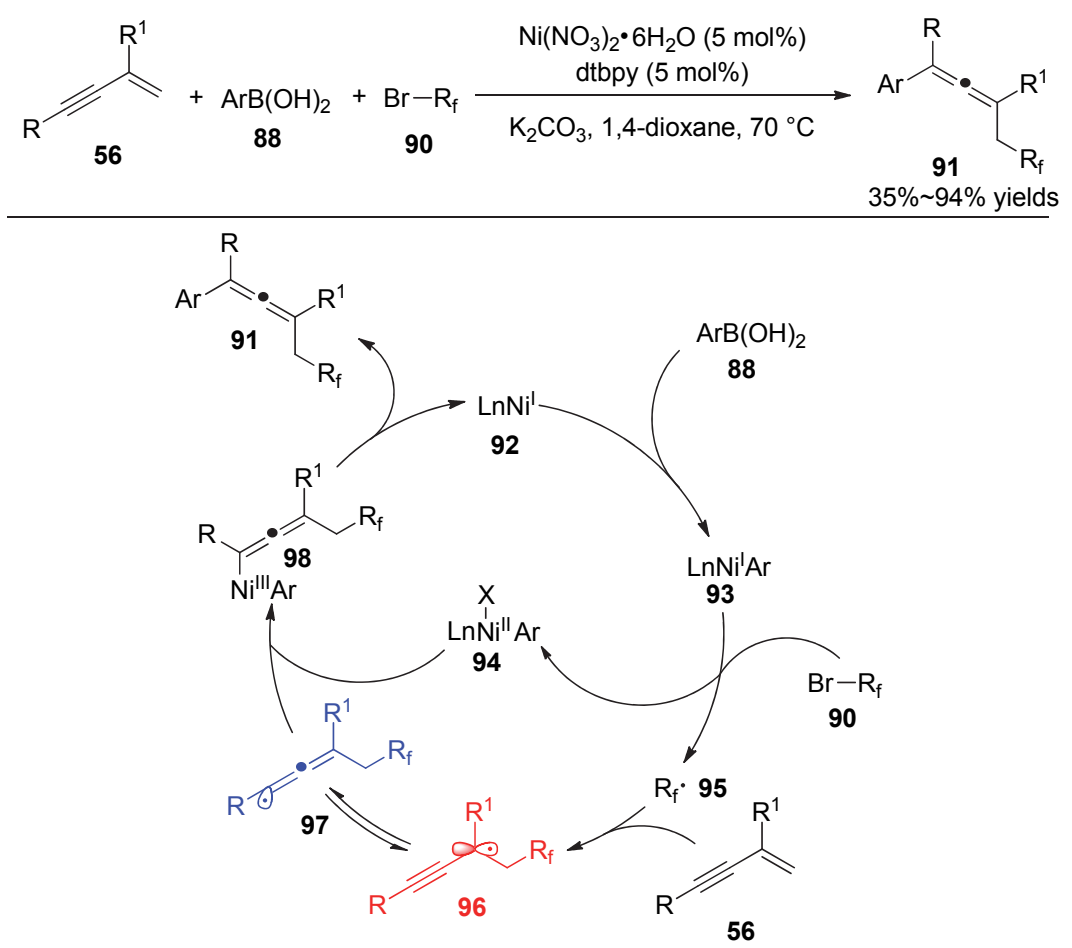

图 18 镍催化 1,3-烯炔的 1,4-双官能化反应

Figure 18 Nickel-catalyzed 1,4-difunctionalization of 1,3-enynes 

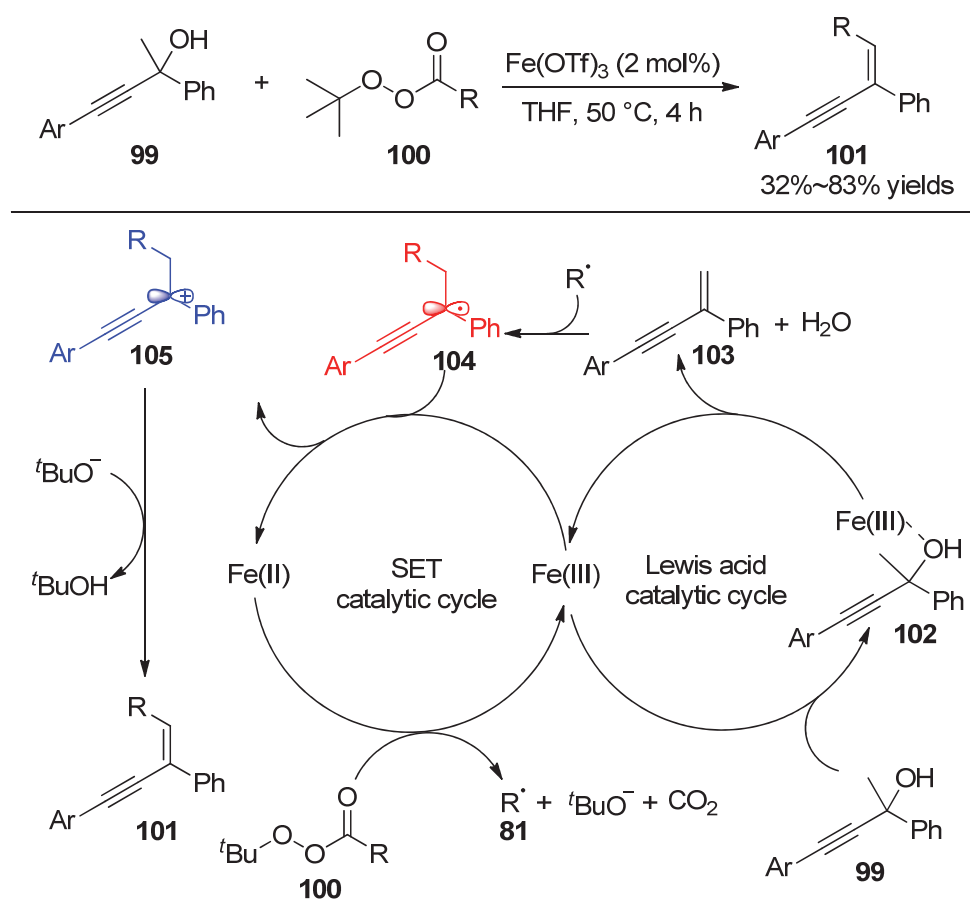

图 19 铁催化的炔丙醇脱水烷基化反应

Figure 19 Iron-catalyzed dehydrative alkylation of propargyl alcohols

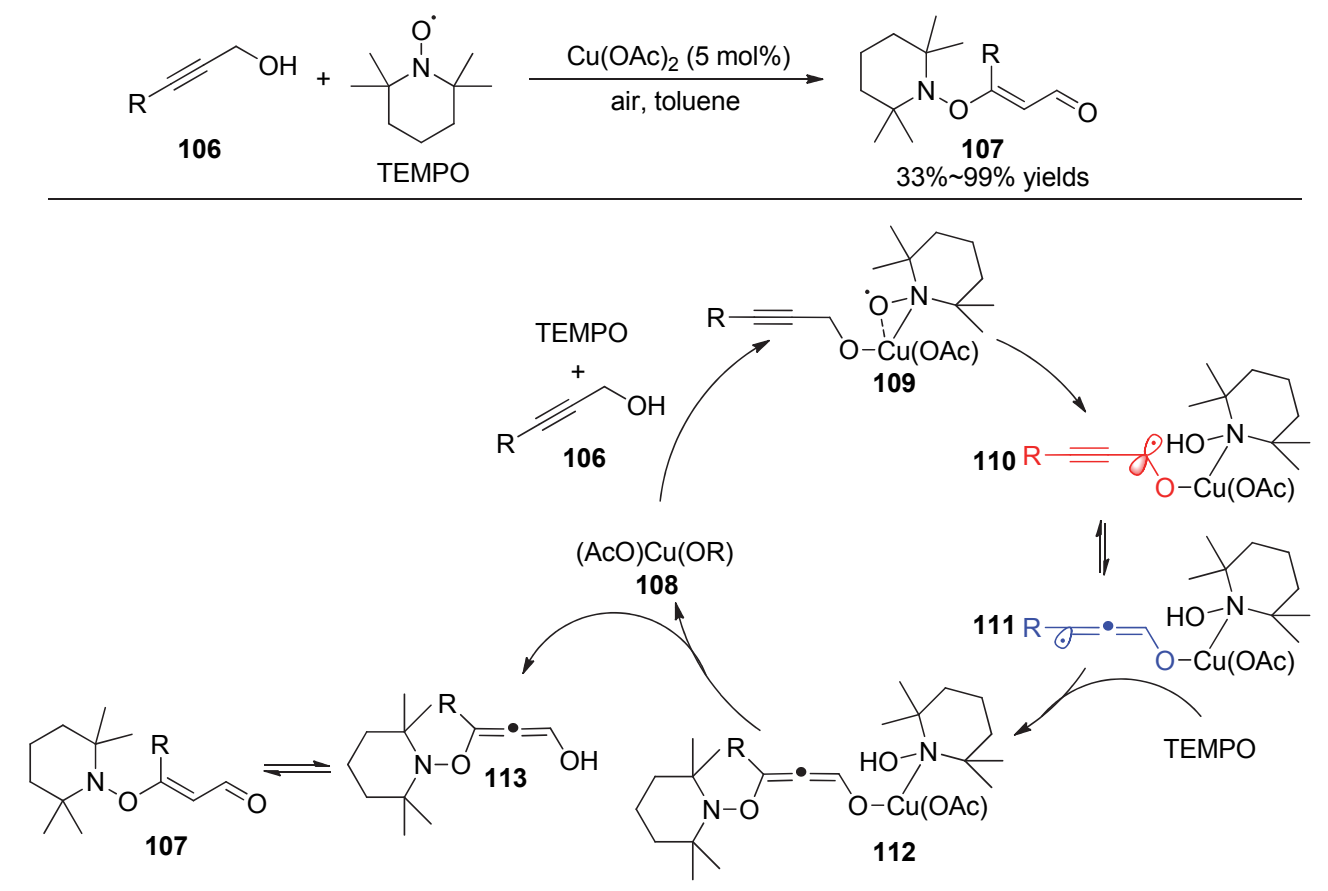

图 20 铜催化乙烯基烷氧胺类化合物的合成

Figure 20 Copper-catalyzed synthesis of vinyl alkoxylamines

化合物的炔丙位官能化反应, 有效合成了新的炔烃类化 合物, 而且也为联烯、1,3-烯炔等其它不饱和化合物的 合成提供了有效的方法.

在今后的研究中, 这一领域仍有三个方面值得努 力: (1)与炔丙基自由基偶联的组分或自由基途径炔丙位 官能化的类型还有待进一步拓展, 目前局限于碳碳键的
形成; (2)炔丙位官能化的原子经济性或步骤经济性有待 进一步改善, 可以考虑过氢原子转移的方式产生炔丙基 自由基 ${ }^{[29]}$; (3)利用炔丙基自由基合成手性联烯类化合物 方面，对映选择性控制还有待进一步改进. 相信通过合 成化学家们的持续努力, 炔丙位自由基参与的反应一定 会更加成熟, 为有机合成的发展助力! 


\section{作者简介}

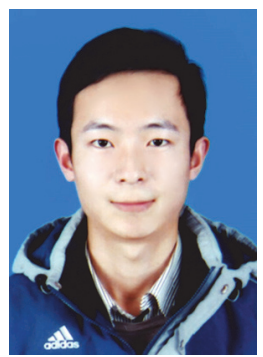

路福东, 1995 年出生于山东安丘, 2017 年在华中农业大学 获得学士学位, 目前在肖文精教授和陆良秋教授指导下攻读 硕士学位. 研究兴趣是可见光催化的不对称反应.

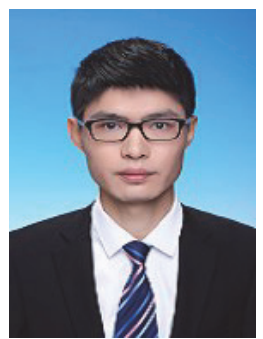

姜烜, 1994 年出生于浙江江山, 2016 年在武汉理工大学获 得学士学位, 目前在肖文精教授和陆良秋教授指导下攻读硕 士学位. 研究兴趣是可见光催化的脱氨基偶联反应.

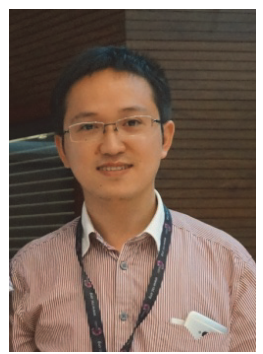

陆良秋教授 1982 年出生于浙江绍兴, 2005 年和 2011 年在 华中师范大学化学学院先后获得学士和博士学位(导师: 肖文 精教授), 随后留校工作. 2011 年至 2013 年以洪堡学者身份赴 德国莱布尼茨催化所 Matthias Beller 教授课题组进行博士后研 究. 2015 年 6 月, 破格晋升为教授. 其研究兴趣主要是过渡金 属催化的偶极环化反应与可见光促进的有机光化学合成研究.

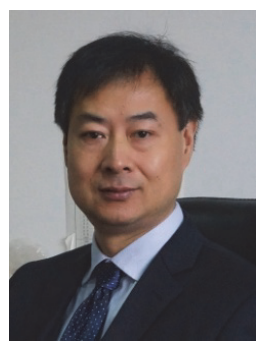

肖文精教授 1965 年出生于湖北公安, 1984 年和 1990 年在 华中师范大学化学系先后获得学士和硕士学位. 1997 年至 2000 年在加拿大渥太华大学化学系学习并获得博士学位(导 师: Howard Alper 教授). 2001 年至 2002 年在美国加州理工学
院化学与化学工程系 David W. C. MacMillan 教授课题组从事 博士后研究. 2003 年加入华中师范大学化学学院. 其研究兴趣 主要是发展新的方法学合成具有潜在生物活性的碳杂环化合 物.

\section{References}

[1] (a) Trost, B. M.; Li, C.-J. Modern Alkyne Chemistry: Catalytic and Atom-Economic Transformations, Wiley-VCH, New York, 2014. (b) Trotus, I. T.; Zimmermann, T.; Schüth, F. Chem. Rev. 2014, 114, 1761. (c) Tiwari, V. K.; Mishra, B. B.; Mishra, K. B.; Mishra, N.; Singh, A. S.; Chen, X. Chem. Rev. 2016, 116, 3086. (d) Huang, D.; Liu, Y.; Qin, A.-J.; Tang, B.-Z. Polym. Chem. 2018, 9, 2853.

[2] Ding, C.-H.; Hou, X.-L. Chem. Rev. 2011, 111, 1914.

[3] (a) Nicholas, K. M.; Pettit, R. Tetrahedron Lett. 1971, 37, 3475. (b) Nicholas, K. M.; Pettit, R. J. Organomet. Chem. 1972, 44, 21.

[4] Melikyan, G. G. Acc. Chem. Res. 2015, 48, 1065.

[5] Geri, R.; Oilizzi, C.; Lardicci, L.; Caporusso, A. M. Gazz. Chim. Ital. 1994, 124, 241.

[6] (a) Miyake, Y.; Uemura, S.; Nishibayashi, Y. ChemCatChem 2009, 1, 342. (b) Zhang, D.-Y.; Hu, X.-P. Tetrahedron Lett. 2015, 56, 283. (c) Xiao, Y.-L.; Pan, Q.; Zhang, X.-G. Acta Chim. Sinica 2015, 73, 383 (in Chinese). (肖玉兰, 潘强, 张新刚, 化学学报, 2015, 73, 383).

[7] Bruneau, C.; Dixneuf, P. H. Metal Vinylidenes and Allenylidenes in Catalysis, Wiley-VCH, Weinheim, 2008.

[8] (a) Kropf, H.; SchrÖder, R.; FÖlsing, R. Synthesis 1977, 894. (b) Alvarez, L. X.; Christ, M. L.; Sorokin, A. B. Appl. Catal. A: Gen. 2007, 325, 303.

[9] Smith, S. W.; Fu, G. C. J. Am. Chem. Soc. 2008, 130, 12645.

[10] Oelke, A. J.; Sun, J.-W.; Fu, G. C. J. Am. Chem. Soc. 2012, 134, 2966.

[11] Pelphrey, P. M.; Popov, V. M.; Joska, T. M.; Beierlein, J. M.; Bolstad, E. S. D.; Fillingham, Y. A.; Wright, D. L.; Anderson, A. C. J. Med. Chem. 2007, 50, 940.

[12] Schley, N. D.; Fu, G. C. J. Am. Chem. Soc. 2014, 136, 16588.

[13] Domingo-Legarda, P.; Soler-Yanes, R.; Quirós-López, M. T.; Buñuel, E.; Cárdenas, D. J. Eur. J. Org. Chem. 2018, 35, 4900.

[14] An, L.; Tong, F.-F.; Zhang, X.-G. Acta Chim. Sinica 2018, 76, 977 (in Chinese). (安伦, 童非非, 张新刚, 化学学报, 2018, 76, 977).

[15] Lu, F.-D.; Liu, D.; Zhu, L.; Lu, L.-Q.; Yang, Q.; Zhou, Q.-Q.; Wei, Y.; Lan, Y.; Xiao, W.-J. J. Am. Chem. Soc. 2019, 141, 6167.

[16] Cheng, J.-K.; Loh, T.-P. J. Am. Chem. Soc. 2015, 137, 42.

[17] Andia, A. A.; Miner, M. R.; Woerpel, K. A. Org. Lett. 2015, 17, 2704.

[18] Miner, M. R.; Woerpel, K. A. Eur. J. Org. Chem. 2016, 1860.

[19] Cheng, J.-K.; Shen, L.; Wu, L.-H.; Hu, X.-H.; Loh, T.-P. Chem. Commun. 2017, 53, 12830.

[20] (a) Chen, Z.-Y.; Zhou, D.-S.; Zhou, J.-Y.; Wu, S.-H. Acta Chim. Sinica 1997, 55, 1138 (in Chinese). (陈招银, 周大顺, 周景尧, 吴 世晖, 化学学报, 1997, 55, 1138). (b) Ma, S.-M. Chem. Rev. 2005, 105, 2829. (c) Lo, V. K.; Wong, M.; Che, C. Org. Lett. 2008, 10, 517. (d) Yang, L.-J.; Ma, J.-A. Acta Chim. Sinica 2016, 74, 130 (in Chinese). (杨丽军, 马军安, 化学学报, 2016, 74, 130). (e) Huang, X.; Ma, S.-M. Acc. Chem. Res. 2019, 52, 1301.

[21] (a) Wartenberg, F.-H.; Junga, H.; Blechert, S. Tetrahedron Lett. 1993, 34, 5251. (b) Alameda-Angulo, C.; Quiclet-Sire, B.; Zard, S. Z. Tetrahedron Lett. 2006, 47, 913.

[22] Soler-Yanes, R.; Arribas-Álvarez, I.; Guisán-Ceinos, M.; Buñuel, E.; Cárdenas, D. J. Chem. Eur. J. 2017, 23, 1584.

[23] Wang, F.; Wang, D.-H.; Zhou, Y.; Liang, L.; Lu, R.-H.; Chen, P.-H.; Lin, Z.-Y.; Liu, G.-S. Angew. Chem., Int. Ed. 2018, 57, 7140.

[24] Zhu, X.; Deng, W.; Chiou, M.-F.; Ye, C.; Jian, W.; Zeng, Y.; Jiao, Y.; Ge, L.; Li, Y.; Zhang, X.; Bao, H. J. Am. Chem. Soc. 2019, 141, 548.

[25] Ye, C.-Q.; Li, Y.-J.; Zhu, X.-T.; Hu, S.-M.; Yuan, D.-Q.; Bao, H.-L. Chem. Sci. 2019, 10, 3632.

[26] Zhang, K.-F.; Bian, K.-J.; Li, C.; Sheng, J.; Li, Y.; Wang, X.-S. Angew. Chem. Int. Ed. 2019, 58, 5069.

[27] Ye, C.-Q.; Qian, B.; Li, Y.-J.; Su, M.; Li, D.-L.; Bao, H.-L. Org. Lett. 2018, 20, 3202

[28] Kang, Y.-W.; Choi, Y.-J.; Jang, H.-Y. Org. Lett. 2014, 16, 4842.

[29] Horn, E. J.; Rosen, B. R.; Chen, Y.; Tang, J.; Chen, K.; Eastgate, M. D.; Baran, P. S. Nature 2016, 533, 77.

(Cheng, B.) 